\title{
PROTECCIÓN CONSTITUCIONAL DEL DERECHO A LA VIDA
}

\author{
Gustavo Cuevas Farren \\ Profesor de Derecho Político y Derecho Constitucional en la \\ Facultad de Derecho de la Universidad de Chile. \\ Decano de la Facultad de Derecho de la Universidad Las Condes.
}

En primer lugar, quiero agradecer en la persona de la Directora de la Escuela de Derecho de la Universidad Católica del Norte, esta invitación para conversar intelectualmente con Uds. sobre un tema de tanta trascendencia como lo es el que ha sido escogido para este Seminario. Felicitarla por el interés en este tipo de eventos, y de paso decirle que me he sentido muy halagado con esta invitación y que siempre me resulta muy agradable venir a La Serena en época que no sea veraniega, porque en verano esta ciudad es difícil de transitar. VIDA"

Nuestro tema es la "PROTECCION CONSTITUCIONAL DEL DERECHO A LA

Habría que comenzar señalando que por primera vez en Chile un texto constitucional asegura y garantiza en forma transparente, e inequívoca, este derecho. Es la primera Carta Magna nacional que contempla, en estos términos, como una de sus garantías, el derecho a la vida. Esto que parece ser tan simple no lo es, en primer lugar, porque los efectos, las implicancias, o el alcance jurídico de este derecho no es una materia fácil, y en segundo lugar, porque los antecedentes históricos, filosóficos, éticos e incluso políticos que rodean y que explican la existencia de una garantía de esta naturaleza son también complejos, 0 , por lo menos, hay muchos antecedentes que deben ser considerados al momento de analizar este derecho.

Es por eso que me voy a permitir apartarme a veces, del texto frío y escueto de la Constitución, para hacer algunas consideraciones que, sin lugar a dudas, son fundamentales para la inteligencia de la norma constitucional. Decir, desde luego, que una mirada de conjunto a la historia, la historia del hombre, demuestra que el ser humano ha ido progresando hacia formas más civilizadas de convivencia, y que precisamente este derecho, el derecho a la vida, es un instrumento básico para regular la violencia al interior de las sociedades. Triste es constatar que la violencia es un hecho constante, deprimente incluso, en el funcionamiento de las sociedades humanas, pero es importante también tener presente que esta regulación, de carácter jurídico, que estamos analizando, es una forma inteligente y civilizada de impedir, o, por lo menos, minimizar, el carácter de dicha violencia.

Recordemos que en todas las sociedades conocidas ha existido algún tipo de prohibición de quitar la vida. Ninguna comunidad podría sobrevivir si permitiera que sus miembros se aniquilarán los unos a los otros sin restricción alguna, pero precisamente a quién proteger de esta amenaza es una cuestión en la cual las 
costumbres han diferido. En diversas sociedades tribales el único delito grave es matar a un miembro inocente de la misma tribu, pero a los miembros de otras tribus se les puede asesinar con impunidad, y esto que acabo de señalar, incluso se ve hoy, desafortunadamente, en extensas zonas geográficas del planeta, particularmente en Africa. En otras naciones o estados mas sofisticados la protección a la vida se ha extendido generalmente a todos, dentro de los límites territoriales de la nación en cuestión, aunque ha habido casos, como en los estados esclavistas, en los que se excluía a una minoría a la que se consideraba cosa u objeto, es decir, los esclavos. (Situación que subsistió en Estados Unidos de Norteamérica hasta bien entrado el Siglo 19).

Hoy en día la mayoría está de acuerdo, en teoría sino en la práctica, que aparte de situaciones especiales como la defensa propia, la guerra, posiblemente la pena capital y una o dos áreas dudosas más, es malo matar a seres humanos independientemente de su raza, religión, clase social o nacionalidad. Se da por supuesta la insuficiencia moral de principios más restringidos que limitan el respeto a la vida sólo a una tribu, raza o nación determinadas. Es decir, en la evolución sociocultural del hombre se ha abierto paso la idea de que es malo, simplemente, matar a otro hombre. Agreguemos que la dimensión violenta de la historia humana se ha manifestado, particularmente, en las guerras. En ellas, se aniquila y extermina, se da muerte al enemigo y al vencido, se destruye todo aquello que a éste le pertenecía y que pudiera eventualmente permitirle recuperarse de la derrota y construir una futura venganza. Cuando se mata al vencido, a veces se elimina también a la familia, a sus amigos, y se roban sus bienes, manifestación del carácter primitivo de la guerra. Esta específica violencia es la más despiadada expresión del desprecio a la vida de otro, que muchas veces, han tenido los seres humanos.

A lo largo del tiempo, las personas han elaborado diferentes formas jurídicas para regular la violencia existente en las sociedades. En épocas más remotas existía el ejercicio de un sistema puro de venganza privada, sin ninguna noción de justicia imparcial que regulara las relaciones sociales y humanas. En una fase más avanzada del desarrollo histórico también nos encontramos con un sistema de venganza privada pero atenuado, en el que aparecen leyes como la "Ley del Talión", la que indica un avance en tanto son una medida y un límite. El "ojo por ojo y el diente por diente" de la Ley del Talión permite devolver el mal causado con otro mal, el mal se devuelve con mal, pero sólo en la misma intensidad y gravedad del que fue causado. Notemos que con el aparecimiento del Estado en la forma que nosotros lo conocemos contemporáneamente, a éste le corresponde la facultad de legislar, juzgar y castigar, para lo cual crea desde un comienzo un sistema jurídico de represión pública.

Recordemos que en la Edad Media las leyes penales son desiguales, se reconocen diferentes sistemas de sanciones aplicables a diversos estamentos de la sociedad y un desmedido arbitrio judicial que, en definitiva, no respeta cabalmente la vida. Durante la Edad Moderna se sigue juzgando y castigando con leyes crueles, las que serán permanentemente cuestionadas, en un intento por humanizar el derecho, anhelo también presenta en la Epoca Contemporánea la que enfrenta, además, junto con este deseo de humanización, nuevas expresiones de criminalidad, como lo son la aparición de los crímenes de guerra y de los crímenes contra la humanidad a los que hizo brillante alusión el Rector Vial en la conferencia anterior. 
No obstante lo anterior, la historia humana también es la progresiva superación de la violencia como forma de relación, es la búsqueda incesante de modos pacíficos de convivencia y de resolución de conflictos. En cierta manera, la historia es la tarea de la propia humanización de los seres humanos. Ciertamente que la sentencia bíblica "No matarás" constituye una primera referencia del derecho a la vida y ello es evidente. Otro documento notable en este sentido es la Carta Magna de 1215, familiar a los estudiantes de Derecho, del Rey Juan I de Inglaterra, que aunque obligó al respeto de las viejas leyes y con ello garantizó los privilegios de los señores feudales, también incluía el reconocimiento de ciertos derechos fundamentales para todos los habitantes del reino y uno de ellos, considerado esencial, era el derecho a la vida. Por su parte, la Declaración de la Independencia de los Estados Unidos redactada por Thomas Jefferson e inspirada en la Declaración de Virginia del mismo país, consagró como derecho inalienable de las personas el derecho a la vida, a la libertad y a la búsqueda de la felicidad. (Quizás este derecho a la vida esté estrechísimamente relacionado con la posible búsqueda de una real felicidad).

La experiencia de la segunda guerra mundial, escenario de crímenes masivos como ya dijimos, motivó a la comunidad internacional para dictar la Declaración Universal de Derechos Humanos, la que en cierta forma ha promovido y fortalecido la vigencia del derecho a la vida, ya que, por ejemplo, después de esta declaración el enemigo en una guerra y el enemigo en las ideas, también es considerado como sujeto de derecho que en tal carácter puede exigir se le respete el derecho a la vida.

En resumen, creo que esta sucinta relación de la evolución histórica, por cierto muy simple, e incompleta, muestra algunos antecedentes que explican el surgimiento jurídico, la aparición en la normativa legal, del derecho que estamos analizando.

Como acabo de señalar, desde el término de la II. Guerra Mundial los países, principalmente motivados por los horrores del conflicto, han suscrito diversos pactos internacionales que consagran la plena vigencia del derecho a la vida. Entre los más importantes, y es útil retenerlos, podemos mencionar los siguientes: la Declaración Universal de 1948 a la que acabo de hacer referencia; la Convención Americana de Derechos Humanos o Pacto de San José de Costa Rica, de 1969; el Pacto Internacional de Derechos Civiles y Políticos, de la misma década; los Convenios de Ginebra de 1949 y los protocolos adicionales a estos Convenios, de 1977, sobre Derecho Humanitario. En estos últimos convenios y protocolos, se prohíbe y sanciona, la violación del derecho a la vida en situación de conflictos internacionales, o sea, de guerra, o incluso en situación de conflicto interno. La Convención para la Prevención y Sanción del delito de Genocidio, de 1948, y la Convención sobre Derechos del Niño (veremos su importancia después), de 1989, completan esta mención.

Ciertamente que los constituyentes chilenos de 1980, tuvieron presente la realidad antes descrita $y$, en cierta forma, creemos que esta nueva garantía constitucional refleja claramente esa tendencia internacional humanitaria y jurídica. Es decir, siendo nuestra Constitución el primer texto que garantiza este derecho en forma imperativa, e inequívoca, ello no expresa tan sólo una inquietud surgida en nuestro medio, sino que también es el reflejo de una inquietud mundial, volcada en la suscripción de dichos pactos internacionales posteriores a la II Guerra Mundial. Esta constatación sirve como puerta de entrada al tema desde un punto de vista jurídico, comprobándose que la ley debe arraigarse en los valores compartidos por la sociedad y. 
Revista de Derecho - Universidad Católica del Norte - Sede Coquimbo - 1997

en consecuencia, para explicarla es menester hacer referencia a los antecedentes históricos o culturales de la norma.

Veamos ahora, brevemente, qué es el derecho a la vida, es decir, una noción del mismo de carácter abstracto aplicable, en cualquier momento y eventualmente en cualquier lugar. En primer lugar, señalemos que este derecho junto con otros de la misma relevancia, es el mínimo necesario, para que el ser humano pueda tener la opción, dentro de la sociedad y en condiciones de igualdad de derechos, de desarrollar plenamente su ser-persona y de hacer efectiva su dignidad. Esta noción, que extraje de los textos, destaca dos aspectos que van a ser reiteradamente, y a veces, subliminalmente, expuestos en esta conferencia, los relativos a la persona humana y a la dignidad de la persona humana. En segundo lugar, específicamente se le puede definir siguiendo al profesor de la Universidad Católica de Chile, Dn. Manuel Guzmán, en la siguiente forma: "Es la facultad jurídica o poder de exigir la conservación y la protección de la vida humana, o sea de ese estado de actividad sustancial propio del hombre". Ya estamos acercándonos, no estamos hablando de nociones filosóficas, sino que estamos hablando de una facultad jurídica específica.

Ahondando en lo anterior, precisemos que cada vez que se otorga un derecho, a cualquier persona, es un poder que se le transfiere a esa persona. Este poder, en la materia que se analiza, tiene la finalidad que acabo de señalar. Además, en términos generales este poder de carácter jurídico sirve para impedir que se prive arbitrariamente de la vida, lo que exige a los Estados tomar medidas para evitar y castigar la privación de la vida de sus súbditos mediante actos criminales o ilegítimos.

En este punto se encuentra toda la problemática del Código Penal, por ejemplo, con el establecimiento de la sanción pertinente, pero también los Estados deben limitar, atención en ésto, deben limitar las ocasiones en las que las propias autoridades del Estado puedan privar de la vida a otra persona cualquiera que sea ésta, y nos anticipa esta observación un tema que analizaremos después, que es el tema de la Pena de Muerte.

Esta es la noción, o concepto general, y con la mirada puesta en ello veamos rápidamente la naturaleza de la protección constitucional contemplada en nuestra Carta Magna. Esta garantía o derecho se encuentra consagrado en el Artículo 19 de la Constitución, artículo este que en general contiene el catálogo de los derechos fundamentales de la persona que el texto asegura. (Todos los números de este artículo apuntan a los derechos básicos del ser humano). Y el Artículo 19 precisamente comienza este catálogo, en los siguientes términos: "La Constitución asegura a todas las personas: número $1^{\circ}$, El derecho a la vida y a la integridad física y síquica de la persona. La ley protege la vida del que está por nacer. La pena de muerte sólo podrá establecerse por delito contemplado en ley aprobada con quórum calificado. Se prohíbe la aplicación de todo apremio ilegítimo". Esta es la norma constitucional, esta es la garantía que se asegura, y éste es, tal como lo acabo de transcribir, el derecho esencial que se consagra, que se puede apreciar que es complejo, no se trata solamente del derecho a la vida, es la protección del que está por nacer, es una advertencia sobre la pena de muerte y es la prohibición determinada y categórica, de todo apremio ilegítimo.

Veamos en primer término cual es el significado y alcance general de esta garantía. Para explicarlo me he basado en lo que señala al respecto uno de los 
redactores del texto constitucional, un distinguido jurista especialista en Derecho Constitucional, el profesor Enrique Evans, quien en una obra relativa a esta materia puntualiza que los principales aspectos vinculados con la vigencia de esta garantía son los siguientes: En primer lugar, se trata de un derecho subjetivo ( $\mathrm{y}$ aquí voy a entrar a un terreno más jurídico, y abstracto, pero es necesario hacer referencia a lo propiamente jurídico para entenderlo) porque importa para su titular una facultad de querer y de obrar de carácter imperativo que debe ser respetada por todos los demás, es decir, todas las personas deben respetar este derecho radicado en un sujeto que es titular del mismo, lo que significa usando una expresión especializada, que es éste un derecho que se ejerce "erga omnes", es decir, respecto de todas y de cualquier persona.

¿Y cuál es el objeto del titular de este derecho, de toda persona como titular de este derecho?. El objeto es el bien jurídico protegido, y éste es la vida, la vida humana, la existencia física-biológica del hombre que está dotado de inteligencia, de voluntad, y agrega Evans, de un fin trascendente. En consecuencia, señala este autor, aparece la vida humana como un bien único, primario y fundamental, protegido por la norma constitucional.

¿Qué otro aspecto principal se destaca en este derecho?. Este otro aspecto es que todo ser humano tiene el derecho esencial de conservar su vida y de exigir que el ordenamiento jurídico se la proteja de los atentados que pueda sufrir por parte de la autoridad o de particulares. Como señala acertadamente Evans, se trate de un derecho "a" la vida, no es un derecho "sobre" la vida, y por ello es que nuestra legislación toca un aspecto que se trató por el Rector Vial, consistente en que el suicidio constituye un hecho ilícito y el auxilio o ayuda al suicidio también lo es, porque nadie posee un derecho que le permita disponer de su propia vida; y es por eso, por vía de ejemplo, que cuando hay un ayunante o ayunantes que quieren acabar con su vida como protesta por algo, cualquier persona puede interponer, como se hace a menudo, un recurso de protección para proteger aquella vida amenazada por el ayuno, porque como dijimos nadie puede disponer de la vida. Es curioso, pero la vida es un bien jurídico no disponible que debe ser preservado aún en contra la voluntad del titular del bien, es decir, de la persona titular del derecho. En consecuencia, la institucionalidad protege el dẹrecho a la vida desde que se inicia la gestación, agrega Evans, es decir, desde el momento en que aquel óvulo junto con el espermatozoide dan origen al genoma, que ya es un ser humano individual.

La Constitución, al proteger la vida del que está por nacer, hace al legislador un doble encargo (toda Constitución puede ser desarrollada por una, o por varias leyes): por una parte, que se ocupe de adoptar las providencias para proteger la existencia del no nacido, como se hace en Chile disponiendo que no se apliquen a la madre que lleva a un hijo en su vientre, sanciones que puedan poner en peligro a la criatura, como lo preceptúa el propio Código Civil que es muy antiguo; o sea, impide que se le puedan aplicar a la madre sanciones, por ejemplo, corporales, que constituyan un riesgo para la vida del no nacido. Y el otro encargo al legislador que la Constitución realiza, consiste en que éste debe rechazar la interrupción provocada del embarazo y debe rechazar asimismo toda legislación permisiva del aborto. Esto es muy importante, lo analizaremos particularmente después, pero es un claro mandato al legislador el de abstenerse de aprobar normas que favorezcan o toleren el aborto. 
El derecho a la vida comprende además el derecho a la integridad física, a la salud y a la legítima defensa, puesto que no basta vivir, sino que es necesario vivir en la plenitud de las cualidades y de los medios orgánicos de que estamos provistos por naturaleza, y vivir bien para conseguir los fines humanos, pudiendo rechazar aun con la fuerza toda agresión injusta. Para los que creemos que la vida es creación divina, agrega el autor que cito, el derecho que nos ocupa es a la vida y no sobre la vida, como precisáramos anteriormente.

Lo último que habría que explicar a este respecto es sobre la pena de muerte. ¿Qué alcance tiene la disposición constitucional en relación con la pena de muerte?, sobre el particular señalaremos que tal disposición constitucional no supone la eliminación de la pena capital de la legislación chilena ni la derogación tácita de los textos legales que la contemplan. Hoy existe evidentemente una marcada reticencia del constituyente respecto de la aplicación de la pena de muerte, como que este exige que su implantación futura requiera de un quórum especial en el Congreso. El hecho cierto es que al margen de las razones de los juristas y filósofos en pro o en contra de esta pena, hay una notable preocupación en las legislaciones, y en la nuestra en particular, por reducir el ámbito de aplicación de este castigo. De manera tal que con respecto a la pena de muerte la Constitución no la ha prohibido, pero ha establecido un sistema, ya volveremos a este punto, muy restrictivo, en cuanto a su aplicación, en concordancia o armonía con la tendencia mundial relativa a la vigencia de esta pena.

Nótese además, acorde con esta explicación sobre el alcance general del texto constitucional, que la Constitución prohíbe los apremios ilegítimos disponiendo que se proteja la integridad física y síquica. Es interesante tener presente que al leer el texto que recoge las discusiones de los redactores de la Constitución, es decir, las actas de la Comisión que la redactó, se constata que se discutió extensa e intensamente si valía la pena consagrar, junto con la protección a la integridad física, la protección de la integridad síquica, por aquello que se entiende que el hombre es a la vez siquis y soma, mente y cuerpo. Finalmente prevaleció la opinión del prestigioso siquiatra señor Roa, en el sentido de que, evidentemente, la integridad síquica es distinta a la integridad física, son dos especies distintas, puesto que la persona reúne las dos características en su ser, la física y la síquica, por lo que necesariamente la siquis y la correspondiente integridad y protección de ella es un bien; un bien, agregó Roa (criterio que convenció a la comisión), cualitativamente similar al de la protección física y a este respecto, Roa ejemplificaba citando el caso de un hombre al que se le puede aniquilar síquicamente sin tocarle un centímetro de su cuerpo, sin dañar un milímetro de su cuerpo. Entre varios ejemplos que el doctor Roa colocaba, estaba el caso de un hombre entrañablemente unido a su cónyuge, a su esposa, al cual se le obliga, atado e impedido de actuar, a ver como los verdugos violan a la esposa frente a él. Sin lugar a duda, dijo Roa, esto importa una mutilación síquica que no lleva consigo ninguna especie de mutilación física, y por lo tanto aconsejó a los redactores de la Constitución que integraran los dos conceptos, consignaran los dos, puesto que a su juicio, y esto es interesante, porque fue el criterio seguido por los redactores, la integridad síquica añadida a la física, conduce a la noción misma de persona humana.

Y esta noción es un terreno importante, de núcleo, porque la persona es el concepto protegido por la Constitución. 
De modo tal que lo expuesto es, en términos muy generales, el alcance de la garantía o derecho que la Constitución asegura en esta materia, debiendo recordarse que es una facultad o derecho subjetivo de todas las personas para proteger un bien jurídico, relevante y fundamental, como lo es la vida biológica, síquica y la existencia misma de las personas. También es un derecho que impide aplicar apremios ilegítimos en contra de cualquiera, encontrándose éstos prohibidos; cualquier apremio de este carácter es rechazado por la Constitución, salvo los que son legítimos, como el arresto de una persona cuando lo ordena el Código Penal, o algunas otras medidas que el reglamento carcelario permite imponer son igualmente un apremio legítimo, pero en general los apremios tendientes a obtener una confesión, o a forzar la siquis de una persona, tendientes a intimidarla o tendientes a plegarla a una determinada idea o facción, son casos de apremios ilegítimos que el constituyente prohíbe categórica e inequívocamente.

Finalmente (tema que retomaré sucintamente después), los redactores de la Constitución también discutieron arduamente en torno a la mantención de la pena de muerte. Hubo consenso, y esto es interesante para la inteligencia de la Constitución, en que la forma amplia como se asegura el derecho a la vida impide la aplicación de la pena de muerte, estoy hablando de exégesis jurídica, de manera que ellos también estuvieron contestes, en que para poder hacer subsistir esta pena aunque fuera en un carácter excepcional, era necesario decirlo así en la Constitución, y así lo expresaron señalando que se mantiene la pena de muerte, incluso a través de una disposición transitoria de la Constitución que ordena mantener la vigencia de las leyes que establecían dicha pena antes de dictarse la nueva Ley Fundảmental.

Pero hay un claro espíritu del constituyente hacia el futuro, en torno a una concepción restrictiva y siguiendo los criterios de la evolución internacional, en el sentido de que a futuro la pena de muerte sólo se podrá aplicar por delitos nominativamente castigados con ella, en una ley aprobada con quórum calificado, es decir, aprobada con una votación especial que exige mayor cantidad de voluntades afirmativas, que exige una mayor cantidad de votos que una ley simple u ordinaria. El debate sobre la procedencia de la pena de muerte está abierto en Chile, y todas las opiniones fundadas sobre este tópico yo creo que son legítimas; retomaremos, como ya dije, brevemente este tema, en una sección siguiente de esta exposición.

Resumiendo lo dicho hasta aquí, he señalado que la Constitución en Chile consagra este derecho por primera vez, pero he agregado que hay un contexto internacional filosófico, social y cultural que convierte a este derecho en una especie de anhelo del Siglo XX, particularmente de la segunda mitad del Siglo XX. He indicado que este anhelo no es tan sólo un anhelo de carácter espiritual, religioso o doctrinal, sino que está plasmado en pactos internacionales con vigencia obligatoria, y con vigencia obligatoria en Chile en virtud del Artículo $5^{\circ}$ de la Constitución cuando están ratificados por nuestro país; y he señalado finalmente que en este orden de ideas, nuestra Constitución se encuentra en sintonía con el mundo contemporáneo, o mejor dicho se puso en sintonía con el mundo contemporáneo al consagrar esta garantía en el Artículo $19^{\circ}$ número 1 , garantía que no es tan simple en sus alcances, porque no abarca únicamente el concepto de vida, sino que abarca igualmente la idea de la vida del que está por nacer, que está protegida, el concepto de apremios y el concepto de la pena de muerte, temas todos ellos de mucha significación que me permitiré retomar luego. 
Por lo tanto, ahora quiero referirme a ciertos problemas importantes o a ciertas situaciones relativas a la vigencia y efectos del derecho a la vida, no poniendo en discusión lo que la Constitución dice, pero bien sabemos que en una materia de tanta relevancia social y de tantos y tan poco previsibles alcances o efectos, hay problemas de enorme magnitud que el legislador, el interprete o el estudioso del Derecho tienen que abordar, y tienen asimismo que hacer un esfuerzo de reflexionar sobre ellos, así es que sobre estos problemas intentaré reflexionar en lo que sigue.

Primero, hay que tener presente que existen ciertos casos en los que privar de la vida a una persona no es considerado una acción arbitraria y por lo mismo no constituye un hecho ilícito. Modifiquemos la frase, indicando que hay ciertos casos en que privar de la vida a una persona no es una acción arbitraria y, por lo tanto, la Constitución no impide que se ejecute esa acción de defensa. ¿Cuáles son?. Todos los casos en los que podemos ser víctimas de injustas agresiones físicas, siempre que la legítima defensa sea proporcional a la agresión sufrida, o sea y, por ejemplo, que para evitar que me maten yo mato, pero no para evitar que me roben "El Mercurio" yo pueda matar al que intenta arrebatarme el diario. Tiene que haber proporcionalidad. Entonces, la privación de la vida de otra persona en este contexto obviamente es una acción no arbitraria, que incluso nuestro Código Penal la contempla como causal de eximente de responsabilidad penal. Aquellos que estudian Derecho Penal, saben que entre las categorías de exención de responsabilidad penal se encuentra la legítima defensa. Este concepto de autodefensa se haya universalmente aceptado, y la razón de este consenso universal radica en el hecho de que su motivación principal es la vida misma que está amenazada, es decir, que cuando yo actúo en legítima defensa no privo de la vida, sino que defiendo mi vida que está amenazada.

Sobre esto hay consenso universal, pero más problemático es el caso de la guerra. Desde muy antiguo se ha aceptado e incluso los pensadores cristianos tienen una opinión uniforme al respecto, que la guerra es una circunstancia que permite privar de la vida, pero se trata de una circunstancia conflictiva, es un hecho controvertido. es una situación dolorosa, y yo agregaría a título muy personal, es una justificación un tanto primitiva. ¿Qué podemos decir sobre la guerra?. En casos bélicos asiste a las personas el derecho de eliminar a otras y este derecho no es cuestionado dado que se asume que en esta hipótesis la muerta acontezca, sólo que el problema aquí es que se supone que es lícito matar, o dicho en otros términos, matar a otro no es cuestionado. El drama de la guerra consiste no tan sólo en la incapacidad de los seres humanos para resolver conflictos en forma pacífica, sino que prevalece la idea de que matar a otro ser humano es una forma aceptada y útil para dirimir los conflictos. Esto lo podemos ver en guerras lejanas, mediatas o recientes, en guerras que el televisor nos trae, cómodamente en nuestras casas, como, por ejemplo, la matanza en Bosnia. El asunto de la guerra es un tema que incluso las Naciones Unidas acogen como temática y acepta tratar. En la carta de las Naciones Unidas la guerra es considerada un medio de autodefensa de los Estados, así como el ser humano tiene derecho a la legítima defensa, en la carta del Organismo los Estados tienen derecho a su autodefensa siempre que sufran una agresión injusta.

Es una realidad, entonces, que hay guerras con destrucción y aniquilación de la vida de otros seres humanos, bajo el auspicio, entre comillas, y participación directa de las Naciones Unidas. Como, por ejemplo, en forma más lejana, sucedió con la guerra de Corea entre los años 49 al 52, cuando las Naciones Unidas formaron un ejército 
básicamente constituido por norteamericanos para evitar o impedir la agresión norcoreana, o más cerca en el tiempo la guerra del Golfo, la expulsión del gobernante iraquí de Kuwait que fue un hecho auspiciado y promovido por las Naciones Unidas.

Evidentemente que el hombre, así como camina a la plena consagración del derecho a la vida, camina igualmente hacia un estatuto de relaciones internacionales que haga cada vez más difícil y estreche cada vez más el campo en el cual la guerra se produce, es decir, una situación en la que la guerra en lo posible no acontezca, porque entonces el exterminio de la vida humana no es individual, no es asesinato de una persona, es un exterminio colectivo. Esto con respecto a la guerra que sigue siendo una forma justificada de quitar la vida a otro, y para hacer todavía un poco más polémica esta reflexión, se nos olvida que ha habido grandes exterminios humanos motivados en consideraciones religiosas, humanitarias o doctrinales, como, por ejemplo, las Cruzadas y otras situaciones similares de guerra santa o religiosa.

También despierta fuerte controversia la pena de muerte, y a lo ya dicho sobre lo que dispone la Constitución convendría agregar lo siguiente: señalé que los redactores de la Ley Fundamental se plantearon la inquietud sobre la existencia de la pena de muerte, y después de debatir intensamente este tema, uno de ellos, un hombre de inspiración cristiana y un jurista católico muy conocido, en consecuencia insoslayablemente partidario de la vida, don Alejandro Silva Bascuñán, opinó entonces que no había contradicción entre el derecho a la vida y la pena de muerte, porque el primero en una sociedad es una garantía, y en cambio, estoy citando, "el derecho a la vida en una sociedad es una garantía y la pena de muerte se aplica al que libremente realizó actos de tal naturaleza como para que la sociedad lo castigue, pero no para quitarle el derecho a la vida" y agrega Silva Bascuñán "sino que para sancionarlo por su actuación contra el ordenamiento jurídico". En consecuencia, la pena de muerte en el espíritu de los redactores, y agrego yo, en el texto mismo de la Constitución, es un modo de castigar la transgresión del ordenamiento jurídico, es una sanción a quienes han cometido una grave transgresión de dicho ordenamiento jurídico. En Chile, como los estudiantes de Derecho lo saben y lo recordamos antes, la pena de muerte se aplica en condiciones muy restrictivas y bajo supuestos procedimentales (procesales) muy rigurosos, como, por ejemplo, que si la aplica el Tribunal de Alzada, Corte de Apelaciones, o la propia Corte Suprema, deben decidirlo por la unanimidad de sus miembros, por la unanimidad de los integrantes del respectivo tribunal. También dijimos que el criterio restrictivo de la Constitución respecto de la pena de muerte está en armonía con los principios del Derecho Internacional, los que favorecen la aplicación de limitaciones a la procedencia de esta pena. Es por lo demás lo que señalan los diversos pactos que cité, de los Derechos Humanos, de San José de Costa Rica, de Ginebra, incluso de los Derechos del Niño; en todos ellos se postula, en armonía con una recomendación de la ONU, que todos los Estados miembros de la Naciones Unidas acaben, en sus legislaciones internas con la pena de muerte, y que aquellos que ya la han abolido, no la restablezcan.

Me quiero detener brevemente aquí para decirles que este tema va más allá de las consideraciones teóricas que acabo de señalar, porque en una sociedad tan compleja, con tanta agresividad expresa o controlada como lo es la nuestra y particularmente las sociedades más desarrolladas que la nuestra, masificadas, con concentraciones urbanas tremendas, lo que favorece los espíritus y los instintos agresivos, el tema de la pena de muerte pasa a ser un tema de primera importancia, los 
crímenes horrendos, reiteradamente horrendos que se cometen en tales realidades sociales hacen que los legisladores, muchas veces superando el texto de los tratados y apartándose de las buenas intenciones internacionales, contemplen o restablezcan la pena de muerte en sus legislaciones.

Quiero citar a este respecto, el caso de los Estados Unidos, que como se sabe tiene un sistema federal en virtud del cual cada uno de sus Estados miembros, que son 50 , dictan su propia legislación en estas materias. En gran parte de estos Estados en la década de los años 50 y 60 se había derogado la pena de muerte, y posteriormente en la mayor parte de ellos se ha restablecido la pena de muerte y no porque la sociedad norteamericana esté más cruel, o despiadada, sino porque precisamente el carácter cruel, inédito y despiadado de los delitos que se cometen en contra de víctimas inocentes los ha llevado a restablecer la pena de muerte. Si yo supiera el día de mañana que efectivamente el ciudadano, cuyo apellido no recuerdo, pero que está detenido por la bomba que hizo explotar en el edificio de un gobierno estadual de los Estados Unidos, provocando la muerte de muchos niños que estaban en el jardín infantil del edificio en ese momento, fuere llevado a juicio y acusado de asesinato, no consideraría improcedente y contrario a la ética, comprobado que le sea el delito, aplicarle precisamente la sanción de muerte, y tengo entendido que probablemente de serle comprobada tal participación criminal, en ese Estado se le va a aplicar dicha pena.

Sin embargo, en Chile el criterio legislativo es restringir la pena de muerte. $\mathrm{Y}$ a este respecto citaré lo que señala un libro de reciente aparición que editó la Corporación Nacional de Reconciliación y Reparación, relativo a la pena de muerte, en el sentido que hemos estado comentando: "La pena de muerte es un recurso que tiene la sociedad para castigar ciertos delitos, para justificarla se han esbozado distintos argumentos como son los de la compensación, medida ejemplarizadora o para desalentar la comisión de delitos, etc. En contra de esta argumentación se puede señalar que la pena en general, que la pena como sanción penal, tiene el objetivo de rehabilitar al delincuente y que la pena de muerte, dada su naturaleza, impide tal rehabilitación. Por otra parte no está probado el perfil disuasivo de la pena de muerte para la comisión de delitos en general, y respecto de ciertos delitos no puede afirmarse que la responsabilidad sea exclusiva del delincuente, porque hay muchos delitos graves, que tienen su explicación en un contexto social de pobreza, de incultura y otros. En consecuencia, responsabilizar a una persona de este acto y más aún castigarla de esta forma, la pena de muerte "constituye una conducta social fuera de toda norma ética". Por último, agrega la publicación, se suma que "la vida humana es sagrada y no existe ninguna razón que faculte al Estado para quitarla". El texto anterior es un buen compendio de argumentos a favor o en contra de esta drástica pena. Agregaremos, siguiendo lo escrito en dicha publicación, que el derecho a la vida no sólo está en peligro en esta situación límite, como es el caso de la pena de muerte, también ocurre que los Estados violan este derecho cuando cometen actos que atentan contra la vida. Se trata de aquellas muertes provocadas por razones políticas, religiosas, raciales, de género u otras que tengan un fundamento discriminatorio. Aun cuando la muerte aparece irremediablemente cuando nos ocupamos del derecho a la vida, en torno a ella, como es lógico suponer, los seres humanos nada pueden hacer, ella es inevitable, lo que el derecho intenta, específicamente el derecho a la vida, es proteger de cualquiera acción arbitraria que pueda afectar la vida, y, por lo tanto, conseguir que aquella clase de muerte, injusta, sea evitable. Implícitamente en esta publicación, la que tiene algún 
sesgo ideológico en mi opinión, se sostiene que la pena de muerte es de suyo una acción arbitraria, por las razones que se señalan y otras que se podrían añadir, y en consecuencia se postula, entre líneas, su abolición.

Yo quiero insistir en un criterio personal, creo que frente a delitos atroces, no poco frecuentes en la sociedad actual, cometidos contra personas verdaderamente desprotegidas e inocentes, la pena de muerte suele ser la única sanción verdaderamente ejemplarizadora que, en primer lugar, restablece el orden social quebrantado, y además, y esto es importante, protege al orden jurídico de la comisión de nuevos atentados graves en contra de él, es decir, quebrantamiento del orden jurídico como consecuencia de suprimirse la vida de personas inocentes. La polémica está abierta y lógicamente puede ser una tema de análisis posterior.

Paso ahora al segundo tema específico vinculado a esta garantía constitucional, el que me parece que es esencial. Creo que es realmente un tema principal de esta problemática y del derecho que consagra la Constitución. ¿A quién pertenece este derecho?. Porque en la brillante, e interesante conferencia del Rector Vial, se discurrió al respecto sobre los conceptos de ser humano, de embrión, de niño, de persona, de anciano. Está bien, yo estimo que esa es la realidad biológica, pero jurídicamente ¿quién es el titular del derecho? Jurídicamente el titular del derecho es la persona, es un derecho que se asegura sólo a las personas, no se asegura a los seres humanos o al homo sapiens, tampoco se asegura a la criatura que tiene vida biológica y racionalidad, únicamente se asegura a las personas y por lo tanto cabe preguntarse: ¿quién es persona?. En parte el Rector Vial abordó esta temática, pero yo quiero ahondarla porque ella tiene un alcance jurídico que hoy es muy preciso en Chile, y todavía más, existe jurisprudencia constitucional de la que se deduce inequívocamente quien es y quien no es persona, y verán de inmediato que dicha jurisprudencia constitucional no sigue exactamente la línea biológica, suele apartarse de ella.

Precisemos en primer lugar, para contestar a la pregunta ¿quién es persona?, que respetar la vida es un principio moral clásico, por ello se admite que la vida de los seres humanos es sagrada e inviolable y este es el supremo fundamento moral para la existencia de este derecho que comentamos. Sin embargo, insisto, la vida que nuestra Constitución garantiza es la de "las personas" y es este el concepto que es necesario precisar. ¿Son análogos los vocablos ser humano y persona? Aquí está el meollo, ¿es lo mismo un ser humano que una persona? ¿O son lo mismo las nociones de ser vivo, homo sapiens que vive, la especie homo sapiens y una persona?. Bueno, si es lo mismo, hay que aceptar que el embrión de $24 \mathrm{hrs}$. es persona, si no es lo mismo para efectos constitucionales el embrión de 24 hrs o de 48 no sería persona. Vamos analizando, para esclarecer este punto voy a citar la opinión de un autor que ha sido controvertido y también lo fue por el Rector Vial, con el que en general discrepo, pero a veces con sus opiniones este autor obliga a pensar, por una parte, y ofrece ejemplos acertados por la otra. Se trata de Peter Singer, el especialista en bioética, quien para facilitarnos la comprensión del concepto de persona escribe lo siguiente: "Es posible dar un significado preciso al vocablo ser humano, podemos utilizarlo como equivalente a miembro de la especie homo sapiens". El término "homo sapiens" es suficientemente conocido, por lo que seguiré con la cita: "determinar si un ser es miembro de una especie concreta es algo que se puede hacer científicamente examinando la naturaleza de los cromosomas en las células de los organismos vivos. En este sentido no existe duda que desde los primeros momentos de su existencia un embrión concebido en un 
óvulo, de un óvulo y un espermatozoide humano, es un ser humano. Estamos claros, y lo mismo ocurre con el ser humano que se encuentra discapacitado síquicamente de la manera más profunda e irreparable, por ejemplo, una persona que tiene una privación de su cerebro absoluta, incluso con un bebé que haya nacido sin cerebro. Pero existe otro uso del término humano, el propuesto por el teólogo y prolífico escritor de temas éticos Joseph Fletcher. Fletcher ha confeccionado una lista de lo que el denomina indicadores de la condición humana entre los cuales se encuentra lo siguiente:

- conocimiento y control de uno mismo;

- sentido del futuro:

- sentido del pasado:

- capacidad de relacionarse con otros;

- preocupación por los demás;

- comunicación; y

- curiosidad.

Este es el sentido del término que tenemos en mente todos cuando alabamos a alguien diciendo que es un verdadero ser humano o que muestra cualidades verdaderamente humanas; cuando uno dice es un verdadero ser humano, tiene cualidades verdaderamente humanas, no queremos decir que tiene una buena biología, quiere decir que tiene estos atributos en alto grado. Al decir esto, naturalmente, no nos estamos refiriendo a la pertenencia de una persona a la especie homo sapiens, cosa que como hecho biológico rara vez se pone en duda, sino que queremos decir que los seres humanos poseen en forma característica ciertas cualidades y que esta persona en concreto las posee en una nivel alto. Estos dos sentidos del término ser humano se superponen pero no coinciden. El embrión que posteriormente será el feto, el niño profundamente discapacitado síquicamente e incluso el neonato, el recién nacido, todos, sin duda, pertenecen a la especie homo sapiens, pero ninguna es consciente de sí mismo, tiene sentido del futuro o capacidad de relacionarse con los demás; por tanto, entre estos dos sentidos hay que concluir que el feto no es persona", sostiene Singer, para hacer más complejo el tema.

De esta cita lo que me interesa destacar, porque tiene importancia para lo que viene a continuación, son las características o indicaciones de lo humano y en esto creo que nadie podría discutirlo, en el sentido de que las características o indicaciones de lo específicamente humano son el conocimiento de si mismo, el sentido del presente, del pasado y del futuro, la capacidad de relación, de comunicación, de creatividad, es decir, aquellos atributos que según decía el autor hacen que digamos a veces que tal sujeto es un gran ser humano o que tiene atributos verdaderamente humanos. Por supuesto que este concepto es restrictivo y se aplica, diríamos glosando a Singer y glosando además la categoría conceptual que estoy señalando, se aplica a la racionalidad. La persona es la que tiene razón, la que puede usar su razón, que tiene capacidad racional. ¿Por qué esto es muy importante? Entre otros motivos, porque algunos meses atrás hubo en Chile un debate extremadamente trascendente, ya que con motivo de la aprobación de una nueva ley sobre trasplantes de órganos se presentó ante el Tribunal Constitucional, un requerimiento de diversos Senadores impugnando la ley, porque a su juicio ella impropiamente le atribuía a la muerte encefálica el carácter de muerte real, en 
circunstancias que de acuerdo al juicio de los impugnadores la muerte encefálica (el encéfalo comprende la corteza cerebral y todas la neuronas que nos permiten pensar), no acaba definitivamente con la vida biológica de la persona.

En efecto, alguien puede encontrarse en situación de muerte, encefálicamente, y seguir su cuerpo viviendo, cosa que ocurre todos los días. No obstante, a juicio de los redactores de la Ley, del Gobierno y de los que la sancionaron, ésto no es así ya que si bien es cierto esa persona no es propiamente un cadáver, en el sentido que le damos a la expresión cadáver, la muerte encefálica constituye realmente el término de la existencia de la persona y luego, y este es el tema esencial, con la muerte encefálica se acabaría la protección constitucional. Reitero, dos posiciones, una alejada de la Ley que sostiene que la muerte implica el término de todas la funciones vitales, no tan sólo las del cerebro, más aún, en esta posición se sostiene que la vida está caracterizada por la capacidad de nutrición. Es decir, cada vez que el organismo puede nutrirse y mantener las correspondientes funciones de nutrición, se está vivo, y por eso hay seres humanos que no obstante estar con un problema de término de la función encefálica, siguen nutriéndose.

La otra posición, referida precedentemente, desestima para definir la muerte la mantención de funciones orgánicas distintas a las cumplidas por el encéfalo.

Ante el Tribunal Constitucional se presentaron varios informes, como el caso de un decapitado que seguía viviendo y nutriéndose como organismo. Ahora bien, ¿Que hay subliminalmente en este proyecto? que dicho sea de paso es ya Ley vigente que se está aplicando. Subliminalmente está la idea de que persona sólo es la que tiene conciencia de sí mismo, cuando deja de tener la conciencia de si mismo dejaría de tener la calidad de persona.

¿El Tribunal que resolvió?, lo estoy citando, porque esta sentencia tiene mucho más trascendencia de la que se le ha dado para la vigencia del derecho constitucional. En primer lugar, el Tribunal se hizo cargo de una serie de informes médicos que se acompañaron, no los voy a detallar, porque no habría tiempo, pero retengo algo interesante, se apoya el Tribunal Constitucional para fallar este caso en el criterio de Pablo Aguilera, un médico y sacerdote del Opus Dei, quien escribió un libro que tuvo gran éxito editorial a comienzo de los 90, con el título "Frontera Vida-Muerte". ¿Y qué distinción hace Aguilera?. Distingue entre la muerte clínica, que a su juicio es la cesación permanente del funcionamiento del organismo, luego la muerte biológica, que a su juicio es la cesación total de la actividad de todas las células de los tejidos, lo que se va dando gradualmente y que es seguida del proceso de descomposición, (perdónenme que esté tocando este tema, pero es fundamental), y distingue por último, para los que tienen fe, la muerte ontológica, última fase que es el momento de la separación del alma y del cuerpo. Tres muertes: muerte clínica, muerte biológica y muerte ontológica. ¿Que hizo el Tribunal? Bueno, apoyándose en diversos informes como acabo de decir, y basándose en esta clasificación, señaló que su juicio esta muerte clínica corresponde a la muerte encefálica; ¿y de qué forma el Tribunal lo argumentó, de qué manera el Tribunal concluyó que la muerte encefálica era la muerte real, unívoca, y definitiva del ser humano?, lo concluyó diciendo que con ella el ser humano terminaba su función de conciencia, dejaba de tener noción de sí mismo y toda la actividad orgánica de su racionalidad cesaba por completo. Y agregó, considerando $6^{\circ}$ del fallo, "A falta de disposición que regule el instante en que dicha protección cesa, 
(del derecho a la vida), debe entenderse que la protección constitucional es hasta la muerte, hecho en virtud del cual se deja de ser persona, y como tal no le son aplicables las garantías inherentes a ella". "Puede concluirse", agrega el Tribunal, "que la Constitución regula la vida desde antes del nacimiento y durante la existencia de la persona la que termina con su muerte natural". ¿Y cuál es la muerte natural de las personas?: la muerte encefálica acorde con esta sentencia.

Entonces ¿cuál es el criterio de nuestra jurisprudencia?; que la muerte es. un hecho natural que marca el fin de la existencia de las personas y el cese de todos sus derechos, entre ellos el derecho a la vida, y esto es importante, este análisis y este fallo, porque sucede que adelantos notables en la ciencia médica hoy permiten mantener viva a una persona, que ha cesado por muchos años de tener funcionamiento cerebral y no obstante sigue viva, o bien el adelanto en la técnica de trasplante de órganos, hace que, aunque sea un poco fuerte decirlo, sea extremadamente discutible concordar en cual es el momento de la muerte ( $y$, por lo tanto, el instante a partir del que es ético y legítimo extraer los órganos).

$Y$ porque es un hecho controvertido el de la naturaleza y el momento de la muerte, cuándo termina la vida y cuándo se da el hecho de la muerte natural, se cuestiona el aprovechamiento de los órganos de una persona, lo que hoy en día se está efectuando de una manera muy intensa. Voy a agregar más, hoy en día en virtud de la vigencia de esta ley, se están aprovechando órganos vivos y no órganos muertos, o sea se utiliza un corazón que late, un corazón que funciona, un pulmón que inhala, etc. (la muerte encefálica no acaba con el funcionamiento de éstos y otros órganos).

El Tribunal señaló además que, examinados los informes científicos antes señalados y teniendo presente lo indicado en otra parte del fallo, se llega a la conclusión de que la abolición total e irreversible de todas las funciones encefálicas constituye la muerte real, definitiva, unívoca e inequívoca del ser humano que acaba con su existencia. Agrega que todas las consideraciones que se exponen en los informes en los que se sostiene la presencia de signos vitales en personas que han sido declaradas en estado de muerte encefálica, aceptan igualmente que tal situación sólo es posible cuando ésta persona permanece conectada a elementos artificiales, como los de ventilación mecánica y otros similares, situación que corrobaría el criterio del Tribunal.

En consecuencia, y quizás esto vaya en especial para los estudiante de Derecho, en Chile el nacimiento ( $y$ aquí me baso en el Código Civil), marca el comienzo de la existencia de las personas y la muerte encefálica marcaría el fin de la existencia de las personas. Lo anterior está claramente expresado así por la jurisprudencia del Tribunal Constitucional, por el Código Sanitario que también habla de muerte encefálica, por la Ley de Transplantes de Organos, y desde muy antiguo, desde el siglo pasado, por el propio Código Civil; entonces ¿porqué esta referencia al fin de las personas?, porque según la jurisprudencia y el texto de la Ley no es lo mismo vida humana que persona, vale decir, si bien en el texto y en el contexto de la Ley hay una protección a la vida antes del nacimiento, existe un mandato al legislador para que proteja la vida antes del nacimiento, la persona misma, el titular del derecho, tiene acotada su existencia, ya que surge o comienza con el nacimiento, y se extingue con la muerte encefálica, no con la muerte orgánica, total, sino que con la muerte encefálica, aun cuando después de la muerte encefálica sobreviva el cuerpo, sea aprovechado o no para fines de transplante. 
Uds. saben que después de la muerte encefálica no tan sólo pueden funcionar diversos órganos, sino que crecen las uñas, crece el pelo, etc.

$Y$ esto, desgraciadamente, también incide en el aborto. ¿Por qué?, porque si bien es cierto existe una cultura nacional respetable y que yo comparto, que abomina del aborto, rechazo del que además dejaron constancia los propios redactores de la Constitución, en la práctica el legislador sólo tiene un mandato que es el de cerrar la puerta al aborto masivo, pero no el de cerrarla enteramente al aborto. Quedó constancia en la Comisión redactora de la Constitución que, desde luego, el aborto terapéutico al que hizo referencia el Rector Vial, no está sancionado, es decir, si bien el legislador no aplaude el aborto terapéutico y tampoco le otorga un carácter ético no lo sanciona como un hecho ilícito. Además, dado que estamos en una sociedad abierta y pluralista, en la que yo tengo mis convicciones pero ellas pueden no ser las del vecino, este delicado tema tiene que ser analizado con los alcances y la amplitud que naturalmente tiene, por una parte, y que deja abierta dicha jurisprudencia, porque yo pienso, y esa es mi convicción, que esta jurisprudencia destapó una caja de pandora, al señalarnos que la Ley, la Constitución y el propio Tribunal, sólo protegen a la persona con conciencia, a la persona que piensa y siente, porque la otra, la que funciona, orgánicamente, la que tiene signos vitales, pero que no tiene conciencia, el legislador la protege sólo en la forma que la Constitución indica, y que es muy restrictiva, pero ese individuo no es titular pleno de derechos.

En otra materia relacionada a ésta, cabe preguntarse ¿El embrión es titular de derechos como persona, en el sentido jurídico? Voy a decir algo fuerte, jurídicamente no, y no, porque antes de los 14 días el embrión no tiene identidad, no hay individualidad, se trata de un conjunto de tejidos con genomas, es decir, con genes, pero que no se sabe si se va a convertir en una, dos o tres personas, por una parte. Además, carece de formaciones nerviosas, y como agregan algunos autores, carece por ello de la remotísima posibilidad de tener conciencia, porque no tiene corteza cerebral, claro esta que, como muy bien expreso el Rector Vial y lo comparto, ése embrión puede llegar a ser un feto y luego un niño que piense mejor que todos nosotros. De acuerdo. Pero ese ánimo altruista, cristiano y bondadoso, no es suficiente para otorgarle el carácter de persona, jurídicamente hablando, a quien no tiene ese carácter según los criterios jurídicos antes expuestos. El tema es tremendamente complejo, porque el legislador chileno estará presionado frente a una evolución permisiva sobre esta materia, que, sin lugar a dudas, es muy delicada.

Sobre el particular, recordemos que en el debate que hubo en la Comisión redactora de la Constitución se dijeron cosas muy fuertes, los miembros de esta Comisión eran todos cristianos, yo diría que todos católicos observantes, y el único que no lo era, era un humanista, con un fuerte sentido de respeto a la humanidad y a las personas, y sin embargo, salvo un miembro que fue Jaime Guzmán, que se opuso al aborto y votó en contra hasta el final por considerar simplemente, un criterio enfático, que el aborto siempre es un homicidio y que como homicidio debe ser penalizado, todos los demás tuvieron consideraciones compasivas no en el sentido de exculpar o de justificarlo, sino de explicar situaciones que podrían motivar y llevar a casos límites en los que el aborto fuere necesario.

Refiriéndose a estas situaciones límites, decía Enrique Ortúzar Escobar, Presidente de la Comisión, ¿que haría un padre, si un insano entra al colegio y viola a 
las niñitas, un insano con una sicopatía agresiva ( $y$ recordemos que en la época que se dio este argumento no existía el Sida y hoy podría ser un insano con Sida), y entre ellas viola a mi hija?, ¿qué pasaría en términos de la humanidad y del derecho a la vida de quien ha sido tan brutalmente agredida, si producto de la violación la hija sufre un embarazo?; por supuesto que esto no puede llevar a justificar el aborto en forma amplia, pero obliga a reflexionar sobre las situaciones excepcionales que lo harían procedente.

Lo que yo quiero señalar con todo esto, es lo complejo que es esta temática aún en su vertiente constitucional, porque en esta vertiente si bien es cierto el derecho a la vida está garantizado, lo está sólo para quien puede ser titular de un derecho, y quien puede ser titular del derecho, es la persona, y según el Tribunal Constitucional la persona aún viva puede dejar incluso de ser tal si ya no tiene funcionamiento encefálico. Aunque no lo dijo expresamente el Tribunal Constitucional, habría que aceptar además que el embrión biológicamente y antes de su individualización como feto, los biólogos y los médicos nos dirán que este embrión no adquiere todavía la característica individual que lo llevará a ser persona, porque sólo es un conjunto de células que se está subdividiendo para llegar a ser un individuo; pero yo creo finalmente que el embrión debe ser protegido desde el momento de la concepción, como por lo demás lo indica la Convención Americana de Derechos Humanos. Esta Convención es la única en el mundo, al sostener que la protección a la vida debe extenderse desde la concepción, criterio vigente en el ámbito latinoamericano, las demás Convenciones hablan solamente de esta protección pero no dicen desde cuando, y de hecho en Canadá, por ejemplo, se acaban de aprobar leyes bastante permisivas con relación a la interrupción del embarazo, lo que yo no quiero decir que sea conveniente, sino que únicamente quiero constatar la presión que se viene encima del legislador nuestro y encima de los conductores políticos en torno a este problema. Generalmente, y comparto firmemente este criterio, el respeto al embrión, el respeto al feto y la prohibición del aborto se basan en otro concepto, cuando se acepta que hay una vida humana potencial. Y como se dijo en un fallo notable de la Corte Suprema de Estados Unidos, impidiendo la interrupción provocada del embarazo después de ciertos meses, "el Estado está obligado" dijo dicha Corte "a proteger la vida humana potencial". Y a mi juicio, imbuido en los criterios latinoamericanos e imbuido además en nuestra cultura cristiano-occidental, esa potencialidad la otorga la concepción, y, en consecuencia, como lo establece la Convención Americana, la vida humana debe estar protegida desde el instante mismo de la concepción.

Comenzando con las conclusiones, debo reiterar que es un notable progreso esta forma de consagración constitucional, porque este derecho es el pilar, es el pie, el fundamento para la vigencia de otros. Y si bien es cierto, como dijo acertadamente el Rector Vial, es muy bueno que el mundo haya llegado a la convicción doctrinal, humana o religiosa de que la vida debe ser intangible, es mucho más seguro que la ley la proteja y es mucho más sólido que la proteja la ley de las leyes, es decir, que esta protección esté consagrada en el propio texto constitucional. ¿Cuál es el alcance del texto constitucional?: el que se explicó anteriormente, no es complejo entender la norma, pero si es complejo entender hasta donde llega su protección, como, por ejemplo, tratándose del fin de las personas.

Se me olvida decir que en lo relativo a la ley de Trasplantes, lo que en mi opinión es realmente muy grave es que se permita extraer algún órgano a una determinada 
persona cuyo cuerpo aún está vivo, literalmente, pero no tan sólo, porque esa persona lo ha permitido, sino porque también lo permiten los que están presentes en el instante de su defunción y que pueden ser únicamente terceros parientes. Es decir, la persona fallecida puede no tener cónyuge ni hijos, pero hay primos, o hay tíos, y entonces el tío dice sí, aprovechen los órganos para un trasplante, otorga su autorización, y así se hace; aquí, incluso, la ley atropella un derecho que los mismos Pactos Internacionales reconocen, como es el de disponer del propio cuerpo para después de muerto, se entiende que disponer del propio cuerpo es un derecho que la persona sólo puede ejercer personalmente, valga la redundancia, por sí misma, y si no se ha dispuesto del cuerpo, tampoco éste pasa a ser un bien disponible, sigue siendo un bien protegido en cuanto al cuerpo se refiere, que es el de pertenecer una persona cuyas funciones encefálicas cesaron. En Chile, en cambio, hemos llegado a la situación en que se puede disponer del cuerpo de un muerto encefálico, lo voy a denominar así, que no es aún un cadáver, por simple disposición de terceros.

Con lo expuesto hasta aquí, quería darles una visión, a lo mejor de contrapunto, sobre el tema del derecho a la vida. Porque cuando uno examina las leyes resulta difícil, a veces resulta complejo aplicarlas al mundo real y sobre todo, acomodarlas al mundo del deber ser biológico, filosófico o religioso. Yo creo que los valores religiosos, pueden ser los fundamentales, pero estimo que el respeto a las demás personas me impone la obligación de respetar igualmente las creencias ajenas y, en consecuencia, el tratar de justificar la extensión que deba dársele a este derecho, y el fundar su vigencia, es una tarea en la que se debe echar mano de todos los argumentos y no tan sólo de los de tipo religioso.

Me asiste la convicción, de que la Convención Americana de los Derechos Humanos, al proteger la vida desde la concepción, está en el camino correcto. Yo creo que nuestro legislador se va a ver enfrentado en el futuro próximo a exigencias muy fuertes con respecto a la vigencia de la protección al no nacido, con respecto a la extensión del aborto y con respecto incluso al tema de la muerte; y en ésto el legislador debe tener, a mi juicio, a dicha Convención como la directriz que guíe su decisión y que en lo posible guíe a los demás poderes públicos y guíe a los jueces (ya vimos que los jueces tienen un criterio muy claro), y esta guía debe traducirse en una política de respeto a la vida humana, la que yo creo que es sagrada por su origen y por su último destino. 